\section{Magellan's search for data}

\section{Washington}

AFTER lengthy delays and one false start, the Magellan planetary probe was last week launched on its way to Venus aboard the space shuttle Atlantis. When it arrives at Venus late next summer, Magellan's radar remote-sensing instruments will peer through the clouds to provide a detailed surface map of the planet that most closely resembles Earth. But the avalanche of data it will relay to Earth during its eight-month mission is expected to double that generated by all previous planetary missions combined, and will stretch the current analysis capabilities of the US National Aeronautics and Space Administration (NASA).

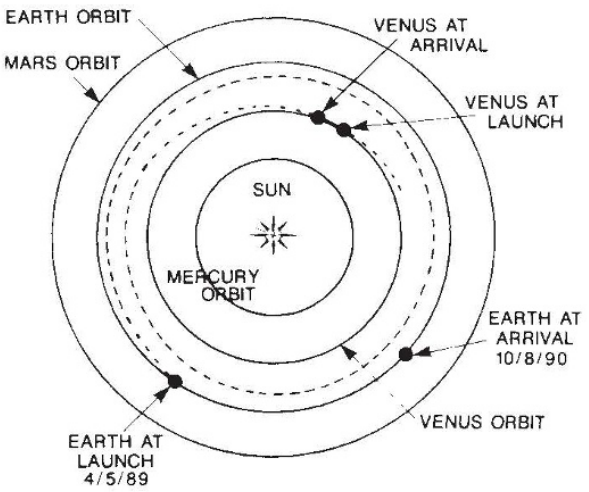

Magellan is the first new planetary probe since the Pioneer spacecraft was sent to Venus in 1978 to provide a rough 60 -mile-resolution map of the planet. Plans for a higher-resolution map of Venus were made later that year, but the launch date was postponed twice and the entire mission was cancelled once because of budget cuts and the greater emphasis on the shuttle programme

The 1986 Challenger accident further delayed a second trip to Venus, as well as postponing plans for the Galileo exploration of Jupiter, the Mars Observer probe and the Ulysses mission to study the poles of the Sun. Magellan secured the fourth spot on the shuttle manifest once it resumed flying last year. The trip to Venus will take one year longer than if it had been launched in 1986, because the different alignment of the planets means it must first travel once around the Sun.

When it arrives in August 1990, the Magellan spacecraft will orbit Venus 1,852 times over a period of eight months to map 90 per cent of the venusian surface in 16-mile swathes. Magellan will map only one side of the planet during each of its three-hour elliptical orbits; when it moves to the other side, it will transmit the collected data to Earth. The resolution of Magellan's synthetic aperture radar is ten times that of the previous Pioneer probe, and should provide enough detail to work out whether or not the crust of Venus is split into tectonic plates or is solid like that of the Moon.

Magellan is the first planetary exploration mission to fly aboard the shuttle and not on an unmanned rocket. When the shuttle was designed, NASA decided to place all space-science flights on the shuttle - a decision that was hotly debated once the shuttle was grounded after the Challenger accident. A second planetary mission, Galileo, is scheduled to be launched by the shuttle in October.

\section{London}

BRITAIN's Ministry of Defence (MOD) was accused last week of being "indifferent" to the long-term health of the country's technological base. After a two-year review of defence research, the government's Advisory Council on Science and Technology (ACOST) says that as large amounts of public money go to defence research, greater benefits should accrue in the civil sector than do at present. In 1986$87, £ 2,400$ million was spent on defence research and development, but less than 20 per cent was aimed at technology with possible applications in the civil sector.

In striking contrast to the policies of most other countries, the British government does not positively encourage technology transfer between civil and military research, says the ACOST report. It recommends that the MOD should take greater account of the country's future technological capability, mainly by encouraging investment in a broader technology base for defence from which both defence and civil sectors may benefit.

The MOD should identify technologies in which it can influence the direction of civil-driven research efforts, participate more with industry in developing technologies with civil as well as military applications and award a greater number of research contracts to universities and research institutes with proven tech-

\section{AIDS}

\section{Transfusion damages}

\section{Paris}

FRENCH haemophiliacs who have contracted the AIDS virus as a result of transfusion with contaminated blood products (before these were systematically screened) will receive an award for damages. A settlement plan outlined by the government last week will give the 12,000 victims who have developed AIDS awards of between FF50,000 and FF150,000 (\$8,000 $\$ 24,000$ ).
While orbiting Venus, Magellan will generate billions of bits of data. To help integrate the mountain of telemetry, NASA has plans for a $\$ 5$ million-per-year Planetary Data System, which will involve a network of 10 computers located at Washington University in St Louis, the Massachusetts Institute of Technology, Brown University, the United States Geological Survey in Flagstaff, Arizona, and the Jet Propulsion Laboratory in Pasadena, California. But the sheer volume of the data will mean that much of it will remain unanalysed for several years.

Carol Ezzell

\title{
UK advisers want civil links
}

nology-transfer mechanisms.

The ACOST report also recommends restructuring of the MOD's own research establishments, which at present are "declining in vitality and viability". Because of recruitment problems, the quantity and quality of staff is now inadequate in some sectors even to maintain the MOD's capacity to act as an informed customer when procuring technology. This problem may be alleviated in part by formation of the new Defence

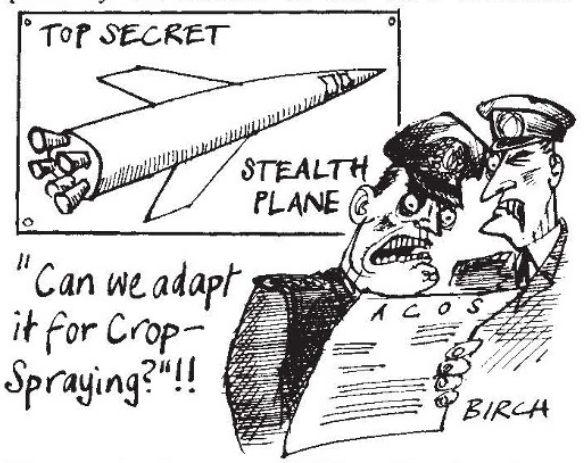

Research Agency which will absorb at least four of the establishments and will not be tied to rigid civil service pay scales (see Nature 338, 287; 1989).

Formation of the agency, which loosens the ties between the ministry and its research establishments, is a step in the right direction, says Sir Charles Reece, chairman of the group which produced the ACOST report. But he said the ministry should focus on fewer areas of technology and aim for higher standards. He would like to see independent technology centres which are national centres of excellence serving both defence and civil markets.

The Ministry of Defence is carrying out its own review of the role of its research establishments, but says the MOD should not have responsibility for technologies unrelated to defence research because that would lead to "muddled roles and inefficiency". It does agree, however, with the broad objective of maximizing cross-fertilization between defence and civil research.

Christine McGourty 